\title{
Acute Diverticulitis Is at Significant Risk of Malnutrition: an Analysis of Hospitalized Patients in a Medicine Department
}

\author{
GianMarco Giorgetti ${ }^{1}$, Federica Fabiocchi ${ }^{1}$,Giovanni Brandimarte ${ }^{2}$, Antonio Tursi ${ }^{3}$
}

1) Digestive Endoscopy and

Nutrition Unit, "S. Eugenio"

Hospital, Rome, Italy

2) Division of

Internal Medicine and

Gastroenterology, "Cristo Re"

Hospital, Rome, Italy

3) Territorial Gastroenterology Service, ASL BAT, Andria, Italy

Address for correspondence:
Antonio Tursi, MD
Servizio di Gastroenterologia
Territoriale
DSS nº 4 , ASL BAT
Via Torino, 49
76123 Andria (BT), Italy
antotursi@tiscali.it

\begin{abstract}
Background \& Aim: The Nutritional Risk Security (NRS2002) System is recommended for hospitalized patients in order to assess their nutritional status. However, studies assessing large-scale systematic screening policies are lacking. The aim of this study was to assess the feasibility of implementing a screening strategy concerning all admissions for diverticular disease (DD) of the colon in the Department of Medicine of a Tertiary Hospital. Methods: All patients suffering from acute diverticulitis (AD) and admitted to the Medicine Department from January 1st to 31 December 2017, were pre-screened by NRS2002 System by the nursing staff of the Nutritional team at the day of the admission. If the pre-screening was positive, the patients were referred to a supplementary assessment performed by a dietician.

Results: The global number of admissions in the observational period was 4,667 and 133 patients suffered from AD. A positive pre-screening test was recorded in 97 (72.9\%) patients: a NRS2002 score > 3, describing a severe impaired nutritional status was found in 61 patients (62.9\%). All 97 patients with a NRS2002 positive screening received initial nutritional support by oral supplements (17 patients, $17.52 \%$ ) or enteral nutrition (22 patients, 22.68\%) or total parenteral nutrition (58 patients, 59.8\%). The mean length of hospital stay for all 133 patients was 6,9 days. However, the length of hospital stay was significantly longer for patients with a positive NRS2002, with a mean of 18 days $(p=0.01)$

Conclusions: A large number of hospitalized patients due to $\mathrm{AD}$ are at nutritional risk and have a significantly longer hospital stay.
\end{abstract}

Key words: Nutritional Risk Security (NRS2002) System - acute diverticular disease; nutritional treatment - hospitalization.

\begin{abstract}
Abbreviations: AD: acute diverticulitis; BMI: body mass index; ESPEN: European Society for Clinical Nutrition and Metabolism; EN: enteral nutrition; ICD-9: International Codes of Disease - 9th Edition; MUAC: mild upper arm circumference; NRS2002: nutritional risk security 2002; ONS: oral nutritional support; TPN: total parenteral nutrition.
\end{abstract}

\section{INTRODUCTION}

Malnutrition is still an underestimated problem throughout the health systems. It is well known that hospital malnutrition can contribute to amplifying disease complications and mortality [1]. Malnutrition arises as the result of an imbalance between the intake and the expenditure of energy and nutrients. About $20-50 \%$ of all hospitalized patients are at risk of malnutrition, depending on the definition, clinical setting, and screening tool used to make the diagnosis [2]. Most of these patients are at nutritional risk already at the time of admission and, malnutrition even develops during hospital stay [3] in up to $48.7 \%$ of patients [4]. It occurs in particular in elderly patients and patients with chronic diseases are more prone to nutritional risk than others $[5,6]$, as recently found also in Emergency Medicine settings [7]. Despite current recommendations, the rate of malnutrition does not seem to decrease significantly. The European Society for Clinical Nutrition and Metabolism (ESPEN) guidelines for nutritional screening in patients admitted to hospital $[8,9]$ recommend a multistep approach to in-hospital malnutrition in order to identify and treat malnutrition adequately.

Acute diverticulitis (AD) of the colon is the most frequent complication in patients with diverticulosis, even if its 
occurrence is lower than previously thought [10]. It's prevalence is high in United States [11], and is increasing in Italy [12]. Although the disease occurrence is generally associated with overweight and obesity [13] that are generally considered signs of over-nutrition, there are very few data about nutritional status in patients with diverticular disease (DD) admitted to hospital.

The aim of the present study was to determine the nutritional status in a cohort of patients suffering from $\mathrm{AD}$ and admitted to hospital, by using Nutritional Risk Screening (NRS)-2002 score.

\section{METHODS}

This retrospective, observational study was conducted in the Medicine Department of the "Sant'Eugenio" Hospital of Rome, Italy (Azienda Sanitaria Locale Roma 2), which serves a population of $>500,000$ inhabitants located in the South of Rome, and having $>200,000$ visits to emergency department every year.

We reviewed the medical charts of patients admitted to our department between January 1st and December 31 2017, having the diagnosis of AD according to ICD-9 (code 56212).

All the enrolled patients underwent nutritional assessment and screening for nutritional risk through the NRS 2002 [14]. The evaluation of the nutritional status included recording the anthropometric parameters and the diseases mentioned in the patient's medical records. For patients who were bedridden and unable to move, the patient's height was estimated from the length of the ulna while the average arm circumference (Mild Upper Arm Circumference, MUAC) was used to estimate the Body Mass Index (BMI) (and thus, indirectly, the weight of the patient).

\section{RESULTS}

During the observational period, 4,667 patients were admitted to the Medicine Department, and 133 suffered from $\mathrm{AD}$ (58\% women, with an average age of $72 \pm 17$ years). All patients suffered from uncomplicated disease, since complicated patients and patients having diverticular bleeding were admitted to surgical department. The nutritional status was recorded: $42 \%$ of patients had normal weight (BMI $18.5-24.9 \mathrm{~kg} / \mathrm{m}^{2}$ ), $34 \%$ were overweight (BMI $25-28.9 \mathrm{~kg} / \mathrm{m}^{2}$ ) and $17 \%$ were obese (BMI $\geq 30 \mathrm{~kg} / \mathrm{m}^{2}$ ).

The NRS2002 was applied to all of them. A positive screening test was recorded in $97(72,9 \%)$ patients, and all of those patients underwent a dietician and nutrition team assessment. A NRS2002 score > 3, describing a severe impaired nutritional status, was found in $61(62.9 \%)$ patients, NRS2002 > 2 was found in $23(23.7 \%)$ patients, and NRS2002 > 1, describing a mild nutritional status impairment, was found in 13 (13.4\%) patients. All 97 patients with a positive NRS2002 screening received initial nutritional support by oral supplements (ONS) (17 patients, $17.52 \%$ ) or enteral nutrition (EN) (22 patients, $22.68 \%$ ) or total parenteral nutrition (TPN) (58 patients, 59.8\%).

The mean length of hospital stay for all 133 patients was 6.9 days. However, the length of hospital stay was significantly longer for patients with a positive NRS2002, with a mean of 18 days $(\mathrm{p}=0.01)$, significantly longer in NRS2002 $>3$ patients $(23$ days) than in NRS2002 $>1$ (8.2 days, $\mathrm{p}=0.001)$.

\section{DISCUSSION}

This is the first study that systematically assessed the presence of malnutrition in patients suffering from $A D$ and, surprisingly, showed that there was an increasing and underestimated risk of malnutrition in this setting. In fact, we found that the NRS2002 detected the presence of nutritional risk in about $73 \%$ of patients, and about $63 \%$ of them were at serious risk. Although overweight and obesity are significant risk factors for $\mathrm{AD}$ occurrence [15], the detection of significant malnutrition in those patients shouldn't be a surprising finding despite overweight and obesity, because it is erroneously thought that overweight and obesity are signs of over-nutrition. On the contrary, especially in elderly (as in-patients generally suffering from DD), malnutrition proportion is really significant $(>49 \%)$ for those whose BMI is over $25 \mathrm{~kg} / \mathrm{m} 2$ [16]. Moreover, this risk seems to be higher to that recently reported in Emergency Medicine setting [7], confirming that patients with AD must be carefully assessed despite their BMI, often needing nutritional support.

Another important finding coming from this study was that hospital stay was significantly longer in patients with positive NRS2002 score. The relationship between nutritional status in DD and length of hospital stay is not completely new. In 1992, Wunderlich and Tobias [17] described that patients with diverticulosis/DD and impaired nutritional status (assessed by serum albumin levels, hemoglobin and hematocrit levels) had a significant longer hospital stay. And we well know how the hospital stay is significant in terms of positive human impact [18]. This is particularly true in geriatric population, which represent the majority of people suffering from DD (and, as expected, the majority of our patients); they are considered a population at risk of malnutrition [5]. In this way, NRS2002 score is really predictive of the disease outcome in patients with chronic and severe diseases [19].

\section{CONCLUSIONS}

This study confirmed that NRS2002 was a useful screening tool to identify patients with $\mathrm{AD}$ at nutritional risk in Medicine Departments, and identified patients needing a closer monitoring program, nutritional therapy (diet) and possibly artificial nutrition (ONS, EN, TPN). Moreover, we found that NRS2002 score may be a significant predictor of disease severity and outcome, which operates independently from the BMI, since a total score of $\geq 3$ can predict the length of hospital stay.

Conflicts of interest: None to declare.

\section{REFERENCES}

1. Cederholm T, Barazzoni R, Austin P, et al. ESPEN guidelines on definitions and terminology of clinical nutrition. Clin Nutr 2017;36:4964. doi:10.1016/j.clnu.2016.09.004

2. National Alliance for Infusion Therapy and the American Society for Parenteral and Enteral Nutrition Public Policy Committee and Board of Directors. Disease-related malnutrition and enteral nutrition therapy: 
a significant problem with a cost-effective solution. Nutr Clin Pract 2010;25:548-554. doi:10.1177/0884533610378524

3. Keller HH, Ostbye T. Nutritional risk and time to death; predictive validity of SCREEN (Seniors in the Community Risk Evaluation for Eating and Nutrition). J Nutr Health Aging 2003;7:274-279.

4. KamiAA, Fernandes R, de Quadros Camargo C, Corsi DM, de Salles RK, de Moraes Trindade EB. Nutrition Risk Screening in Patients Admitted to an Adult Emergency Department of a Brazilian University Hospital. Nutr Clin Pract 2017;32:84-91. doi:10.1177/0884533616656339

5. Bernabeu-Wittel M, Jadad A, Moreno-Gaviño L, et al. Peeking through the cracks: an assessment of the prevalence, clinical characteristics and health-related quality of life (HRQoL) of people with polypathology in a hospital setting. Arch Gerontol Geriatr 2010;51:185-191. doi:10.1016/j. archger.2009.10.006

6. Edington J, Boorman J, Durrant ER, et al. Prevalence of malnutrition on admission to four hospitals in England. The Malnutrition Prevalence Group. Clin Nutr 2000;19:191-195. doi:10.1054/clnu.1999.0121

7. Giorgetti GM, De Toma P, Di Pietro E, et al. Assessment of nutritional status and therapy in emergency Medicine settings. J Biol Regul Homeost Agents 2018;32:1573-1577.

8. Volkert D, Berner YN, Berry E, et al. ESPEN Guidelines on Enteral Nutrition: geriatrics. Clin Nutr 2006;25:330-360.doi:10.1016/j.clnu.2006.01.012

9. Kondrup J, Allison SP, Elia M, Vellas B, Plauth M; Educational and Clinical Practice Committee, European Society of Parenteral and Enteral Nutrition (ESPEN). ESPEN guidelines for nutrition screening 2002 Clin Nutr 2003;22:415-421. doi:10.1016/s0261-5614(03)00098-0

10. Shahedi K, Fuller G, Bolus R, et al. Long-term risk of acute diverticulitis among patients with incidental diverticulosis found during colonoscopy. Clin Gastroenterol Hepatol 2013;11:1609-1613. doi:10.1016/j.cgh.2013.06.020
11. Peery AF, Dellon ES, Lund J, et al. Burden of gastrointestinal disease in the United States: 2012 update. Gastroenterology 2012;143:1179-1187. e3. doi:10.1053/j.gastro.2012.08.002

12. Binda GA, Mataloni F, Bruzzone M, et al. Trends in hospital admission for acute diverticulitis in Italy from 2008 to 2015. Tech Coloproctol 2018;22:597-604. doi:10.1007/s10151-018-1840-Z

13. Aune D, Sen A, Leitzmann MF, Norat T, Tonstad S, Vatten LJ. Body massindex and physical activity and the risk of diverticular disease: a systematic review and meta-analysis of prospective studies. Eur J Nutr 2017;56:2423-2438. doi:10.1007/s00394-017-1443-x

14. Kondrup J. Nutritional-risk scoring systems in the intensive care unit. Curr Opin Clin Nutr Metab Care 2014;17:177-182. doi:10.1097/ MCO.0000000000000041

15. Tursi A. Dietary pattern and colonic diverticulosis. Curr Opin Clin Nutr Metab Care 2017;20:409-413. doi:10.1097/ MCO.0000000000000403

16. Özkaya I, Gürbüz M. Malnourishment in the overweight and obese elderly. Nutr Hosp 2019;36:39-42. doi:10.20960/nh.02062

17. Wunderlich SM, Tobias A. Relationship between nutritional status indicators and length of hospital stay for patients with diverticular disease. J Am Diet Assoc 1992;92:429-433.

18. Southern WN, Berger MA, Bellin EY, Hailpern SM, Arnsten JH. Hospitalist care and length of stay in patients requiring complex discharge planning and close clinical monitoring. Arch Internal Med 2007;167:1869-1874. doi:10.1001/archinte.167.17.1869

19. Cui J, Wan Q, Wu X, et al. Nutritional Risk Screening 2002 as a Predictor of Outcome During General Ward-Based Noninvasive Ventilation in Chronic Obstructive Pulmonary Disease with Respiratory Failure. Med Sci Monit 2015;21:2786-2793. doi:10.12659/MSM.894191 